\title{
BMJ Open Algorithmic surveillance of ICU patients with acute respiratory distress syndrome (ASIC): protocol for a multicentre stepped-wedge cluster randomised quality improvement strategy
}

Gernot Marx, ${ }^{1,2}$ Johannes Bickenbach, ${ }^{1,2}$ Sebastian Johannes Fritsch (D) ,1,2,3 Julian Benedict Kunze (D) ,1,2 Oliver Maassen, ${ }^{1,2}$ Saskia Deffge, ${ }^{1,2}$ Jennifer Kistermann, ${ }^{1,2}$ Silke Haferkamp, ${ }^{2,4}$ Irina Lutz, ${ }^{2,4}$ Nora Kristiana Voellm, ${ }^{2,4}$ Volker Lowitsch, ${ }^{2,5}$ Richard Polzin, ${ }^{2,6}$ Konstantin Sharafutdinov, ${ }^{2,6}$ Hannah Mayer, ${ }^{2,7}$ Lars Kuepfer, ${ }^{2,7}$ Rolf Burghaus, ${ }^{2,7}$ Walter Schmitt, ${ }^{2,8}$ Joerg Lippert, ${ }^{2,8}$ Morris Riedel, ${ }^{2,3}$ Chadi Barakat, ${ }^{2,3}$ André Stollenwerk, ${ }^{2,9}$ Simon Fonck, ${ }^{2,9}$ Christian Putensen, 2,10 Sven Zenker, ${ }^{2,10,11}$ Felix Erdfelder, ${ }^{2,10,11}$ Daniel Grigutsch, 2,10,11 Rainer Kram, ${ }^{2,12}$ Susanne Beyer, ${ }^{2,13}$ Knut Kampe, ${ }^{2,14}$ Jan Erik Gewehr, ${ }^{2,15}$ Friederike Salman, ${ }^{2,14}$ Patrick Juers, ${ }^{2,15}$ Stefan Kluge, ${ }^{2,14}$ Daniel Tiller, ${ }^{2,16}$ Emilia Wisotzki, ${ }^{2,16}$ Sebastian Gross, ${ }^{2,17}$ Lorenz Homeister, ${ }^{2,17}$ Frank Bloos (D) ,2,18 André Scherag (1) ,2,19 Danny Ammon, ${ }^{2,20}$ Susanne Mueller, ${ }^{2,19}$ Julia Palm (D) , 2,19 Philipp Simon (D) ,2,21 Nora Jahn, ${ }^{2,21}$ Markus Loeffler, ${ }^{2,22}$ Thomas Wendt, ${ }^{2,23}$ Tobias Schuerholz, ${ }^{2,24}$ Petra Groeber, ${ }^{2,25}$ Andreas Schuppert ${ }^{2,6}$

To cite: Marx G, Bickenbach J, Fritsch SJ, et al. Algorithmic surveillance of ICU patients with acute respiratory distress syndrome (ASIC): protocol for a multicentre steppedwedge cluster randomised quality improvement strategy. BMJ Open 2021;11:e045589. doi:10.1136/ bmjopen-2020-045589

- Prepublication history for this paper is available online. To view these files, please visit the journal online (http://dx.doi. org/10.1136/bmjopen-2020045589).

Received 06 October 2020 Revised 02 February 2021 Accepted 17 February 2021

Check for updates

(c) Author(s) (or their employer(s)) 2021. Re-use permitted under CC BY-NC. No commercial re-use. See rights and permissions. Published by BMJ.

For numbered affiliations see end of article.

Correspondence to Professor Gernot Marx; gmarx@ukaachen.de

\section{ABSTRACT}

Introduction The acute respiratory distress syndrome (ARDS) is a highly relevant entity in critical care with mortality rates of $40 \%$. Despite extensive scientific efforts, outcome-relevant therapeutic measures are still insufficiently practised at the bedside. Thus, there is a clear need to adhere to early diagnosis and sufficient therapy in ARDS, assuring lower mortality and multiple organ failure.

Methods and analysis In this quality improvement strategy (QIS), a decision support system as a mobile application (ASIC app), which uses available clinical realtime data, is implemented to support physicians in timely diagnosis and improvement of adherence to established guidelines in the treatment of ARDS. ASIC is conducted on 31 intensive care units (ICUs) at 8 German university hospitals. It is designed as a multicentre steppedwedge cluster randomised QIS. ICUs are combined into 12 clusters which are randomised in 12 steps. After preparation (18 months) and a control phase of 8 months for all clusters, the first cluster enters a roll-in phase (3 months) that is followed by the actual QIS phase. The remaining clusters follow in month wise steps. The coprimary key performance indicators (KPIs) consist of the ARDS diagnostic rate and guideline adherence regarding lung-protective ventilation. Secondary KPIs include the prevalence of organ dysfunction within 28 days after diagnosis or ICU discharge, the treatment duration on ICU and the hospital mortality. Furthermore, the user acceptance and usability of new technologies in medicine
Strengths and limitations of this study

- Continuous monitoring of routinely collected parameters to improve the timely diagnosis in acute respiratory distress syndrome, especially of frequently underdiagnosed mild stages as well as to increase guideline adherent therapy.

- Usage of mobile devices on intensive care units to shorten response time onto clinically relevant events in critical care medicine.

- Realisation of interoperability of heterogeneous medical routine data to improve its use for research and improvement of care and to enable cross-site data exchange.

- No mandatory changes in clinical care, as treatment remains in the full responsibility of the physician in charge.

- Statistic analysis will not comply with the standards of a regular clinical trial, since a quality improvement strategy was chosen to prove feasibility and means of implementation.

are examined. To show improvements in healthcare of patients with ARDS, differences in primary and secondary KPIs between control phase and QIS will be tested.

Ethics and dissemination Ethical approval was obtained from the independent Ethics Committee (EC) at the RWTH Aachen Faculty of Medicine (local EC reference number: EK 102/19) and the respective data protection officer in March 
2019. The results of the ASIC QIS will be presented at conferences and published in peer-reviewed journals.

Trial registration number DRKS00014330.

\section{INTRODUCTION}

Acute respiratory distress syndrome (ARDS) is a lifethreatening medical condition associated with mortality rates ranging approximately from $25 \%$ to $46 \%$ across all severities and can be even higher when associated with dysfunction of other organs. ${ }^{12}$ Depending on the severity of hypoxia which is defined by the arterial oxygen tension $\left(\mathrm{p}_{\mathrm{a}} \mathrm{O}_{2}\right) /$ fractional inspired oxygen $\left(\mathrm{F}_{\mathrm{i}} \mathrm{O}_{2}\right)$ ratio (Horovitz quotient), moderate ARDS (with a $\mathrm{p}_{\mathrm{a}} \mathrm{O}_{2} / \mathrm{F}_{\mathrm{i}} \mathrm{O}_{2}$ ratio 101-200) has been reported to occur in 16-23 and severe ARDS (with a $\mathrm{p}_{\mathrm{a}} \mathrm{O}_{2} / \mathrm{F}_{\mathrm{j}} \mathrm{O}_{2}$ ratio $\leq 100$ ) in 58-79 per 100000 inhabitants per year. ${ }^{3}$ Lung-protective ventilation, that is, the use of low tidal volumes and the limitation of airway pressures, has been shown to improve outcomes compared with mechanical ventilation with high tidal volumes and airway pressures. Despite this outcomeimproving strategy, the large multicentre, observational 'LUNG SAFE'-trial observed a low adherence to lungprotective ventilatory strategies and guidelines associated with a high mortality rate up to $46 \%$ in severe ARDS. ${ }^{1}$ An additional finding of the LUNG SAFE-trial was that up to $39 \%$ of the ARDS cases were not diagnosed by the physicians, which suggests procedural and infrastructural deficits. Particularly early and mild or moderate ARDS often remains unrecognised until respiratory dysfunction of the patient has deteriorated further and severe hypoxia is present. By implementing consistent lung-protective ventilation, as described in the German guideline 'Invasive ventilation and use of extracorporeal procedures in acute respiratory insufficiency', 4 significant improvement in the prognosis of this disease entity should be achieved. ${ }^{56}$ However, implementation of these therapy principles cannot be achieved when ARDS is not or not early enough diagnosed. Hence, improvements in both ARDS screening as well as in implementation of evidence-based therapeutic measures are urgently needed. Improvements of procedural and infrastructural deficits might be provided by intelligent technical solutions. ${ }^{78}$ A software approach preprocessing data from electronic health records (EHRs) and providing diagnostic data and treatment recommendations on a mobile device might be such a solution. This approach has been taken by the use case 'Algorithmic Surveillance of intensive care unit (ICU) patients with ARDS' (ASIC). ASIC is an integral part of the 'Smart Medical Information Technology for Healthcare' (SMITH) project. ${ }^{9}$ SMITH is one of four consortia funded by the 'Medical Informatics Initiative' of the German Federal Ministry of Education and Research. ${ }^{10}$

The objective of our quality improvement project is to improve ARDS detection and guideline adherence in the treatment of mechanically ventilated ARDS-patients by implementing an application software (app) provided on a mobile device and consecutively improve outcome in this patient population.

\section{METHODS AND ANALYSIS \\ ASIC app}

The ASIC app is a mobile, technical support system to facilitate diagnosis and therapy of ARDS and has been specifically developed for this project. It operates system independently on different devices. As part of the ASIC project, it is intended to be used on a mobile device (eg, tablet, smartphone). The data used by the ASIC app are obtained from the local EHR. According to these data, a diagnosis of ARDS can be made by the physician according to the Berlin Criteria. ${ }^{11}$ Manual entries are required for the findings, which are not documented automatically, like radiographic reports. Due to these functions, the ASIC app only displays a compilation of already existing and documented clinical routine data.

ARDS is suspected in mechanically ventilated patients ( $\geq 24$ hours duration) by automated ASIC app dependent positive screening of respiratory dysfunction. The duration of mechanical ventilation, the $\mathrm{p}_{\mathrm{a}} \mathrm{O}_{2} / \mathrm{FiO}_{2}$ ratio and the positive endexpiratory pressure (PEEP) are extracted and screened by the ASIC app automatically. An ARDS suspicion is defined as deterioration of the $\mathrm{p}_{\mathrm{a}} \mathrm{O}_{2} / \mathrm{FiO}_{2}$ ratio $\leq 300 \mathrm{~mm} \mathrm{Hg}$ that occurs under a PEEP $\geq 5 \mathrm{cmH}_{2} \mathrm{O}$. In case of ARDS suspicion, the physician will be informed and has to evaluate a potential diagnosis by checking the non-automated criteria of ARDS. These include (1) an acute onset of lung injury within 1 week of an apparent clinical insult and with progression of respiratory symptoms, (2) presence of bilateral opacities on chest imaging (chest radiograph or CT) not explained by other lung pathology (eg, effusion, lobar/lung collapse or nodules) and (3) respiratory failure not explained by heart failure or volume overload. According to the Berlin definition, three severity stages of ARDS (mild, moderate, severe) are categorised based on the degree of hypoxemia using the $\mathrm{p}_{\mathrm{a}} \mathrm{O}_{2} / \mathrm{F}_{\mathrm{i}} \mathrm{O}_{2}$ ratio. ${ }^{11}$ If the diagnosis has been made by the physician, the ASIC app displays the relevant recommendations of the German S3 guideline 'Invasive ventilation and use of extracorporeal procedures in acute respiratory insufficiency' ${ }^{4}$ and requests the physician to evaluate applicability of these recommendations for the individual patient. Responsibilities for diagnostic and therapeutic decisions remain with the physicians in charge. If the ARDS diagnosis is not verified, a 24-hour blocking period follows, in which the app does not issue any further notifications. If screening for ARDS remains positive, the app will ask the physician for re-evaluation after 24 hours.

\section{Project design}

This paragraph describes the initial design of the project as it was planned before the start of control phase. The project is designed as a multicentre stepped-wedge cluster randomised quality improvement strategy (QIS) ${ }^{12}$ It will be conducted at 8 German university hospitals: Aachen ( 8 


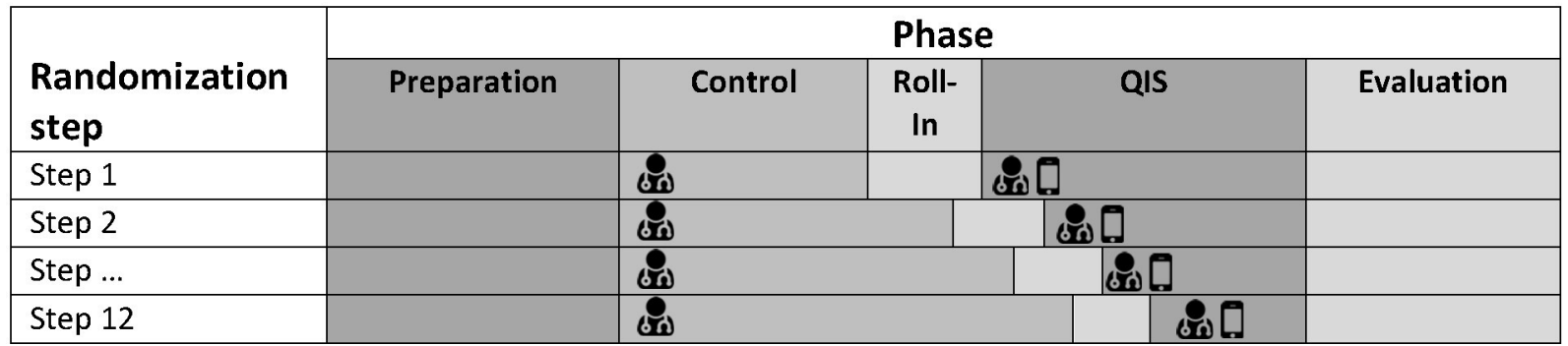

Figure 1 Stepped-wedge design. During the control phase, ARDS detection is performed according to local standard by the physician in charge with beginning of the QIS phase, physician's ARDS diagnosis is supported by the ASIC app. ARDS, acute respiratory distress syndrome; QIS, quality improvement strategy.

ICUs/96 beds), Bonn (4/58), Duesseldorf (1/16), Halle a. d. Saale (2/30), Hamburg-Eppendorf (10/116), Jena $(2 / 50)$, Leipzig $(3 / 78)$ and Rostock (1/23). Since not all of these 31 ICUs are technically and organisationally independent, the dependent ICUs will be summarised into clusters. This results in a total of 12 clusters available for randomisation, of which each will be randomised to one of the 12 steps. After a preparation phase of 18 months, all participating clusters start with a control phase (standard of care) simultaneously. After 8 months, the first clusters enter the roll-in phase (3 months) that is followed by the actual QIS phase. The remaining clusters follow in a stepwise fashion with 1 month between each step (figure 1). During the control phase, the status quo in diagnosis and therapy of ARDS is recorded without any interventions and change in clinical routine. According to the randomisation scheme, the ASIC app will be implemented on the participating ICUs during the roll-in phase to ensure clinical and technical functionality and adequate training of the ICU staff. 3 months later, the QIS phase will start, using the ASIC app in clinical routine. In this phase, the physicians will be assisted to optimise diagnosis and guideline-adherent therapy of ARDS by the ASIC app. Except for the app-usage, there are no further changes in routine caregiving. The final evaluation of primary and secondary key performance indicators (KPIs) (see below) will take place in the evaluation phase.

\section{Population under surveillance}

All patients $\geq 18$ years of age in the participating ICUs, who are mechanically ventilated for at least 24 hours, will be admitted to the project. According to pre-existing data from the local EHRs, we expect approximately 5000 patients per year to be surveyed within the project.

\section{Key performance indicators}

The coprimary KPIs of the project consist of the diagnostic rate, defined as the proportion of patients diagnosed with ARDS out of all monitored patients, and guideline adherence regarding lung-protective ventilation, defined as shown below (see table 1).

Secondary KPIs include the prevalence of organ dysfunction within 28 days after ARDS diagnosis or ICU discharge (whatever occurs first). The treatment duration on ICU and the hospital mortality after ARDS diagnosis will be assessed at hospital discharge, irrespective of length of stay.

Furthermore, the user acceptance and usability of new technologies in medicine, such as mobile devices or clinical decision support systems will be examined. Therefore,

Table 1 Coprimary and secondary key performance indicators of ASIC

\section{Coprimary key performance indicators}

1. Diagnostic rate, defined as the proportion of patients diagnosed with ARDS out of all monitored patients

\section{Secondary key performance indicators}

1. Prevalence of organ dysfunction within 28 days after diagnosis of ARDS or ICU discharge (whatever occurs first), defined as days without need of following measures:

- Mechanical ventilation

- Use of vasopressors

- Renal replacement therapy

2. Guideline adherence regarding lung-protective ventilation, defined as the percentage of time within 28 days after ARDS diagnosis or ICU discharge (whatever occurs first), during which the mechanical ventilation parameters fulfil the following criteria:

- Tidal volume $\left(\mathrm{V}_{\mathrm{t}}\right): \leq 6 \mathrm{~mL} / \mathrm{kg} \mathrm{KG}$ (predicted)

- Endinspiratory pressure $\left(\mathrm{P}_{\mathrm{E}}\right): \leq 30 \mathrm{cmH}_{2} \mathrm{O}$

- Positive endexpiratory pressure (PEEP) $\geq 5 \mathrm{cmH}_{2} \mathrm{O}$

- Driving pressure $\left(\triangle \mathrm{p}=\mathrm{P}_{\mathrm{El}} \mathrm{PEEP}\right) \leq 15 \mathrm{cmH}_{2} \mathrm{O}$

\section{Treatment-duration on ICU after ARDS diagnosis}

\section{Hospital mortality after ARDS diagnosis}

4. Acceptance and usability of the ASIC app and the mobile device:

a. Pre-Roll-In of the ASIC app.

b. Post-Roll-In (6 months) of the ASIC app.

ARDS, acute respiratory distress syndrome; ICU, intensive care unit. 
Table 2 Patient-related data acquisition

\section{Acquired data at inclusion}

Demographic data Age, sex, height, weight, body mass index, predicted bodyweight (according to the ARDS network)

\section{Acquired data at diagnosis of ARDS}

Therapeutic interventions Prone positioning

\section{Acquired data $\mathbf{2 8}$ days after diagnosis of ARDS or ICU discharge (whatever occurs first)}

\begin{tabular}{|c|c|}
\hline Guideline adherence & $\begin{array}{l}\text { Time fraction of guideline } \\
\text { adherent therapy. Included } \\
\text { parameters: } \\
\text { Tidal volume }\left(\mathrm{V}_{\mathrm{t}}\right): \leq 6 \mathrm{~mL} / \mathrm{kg} \\
\text { predicted bodyweight } \\
\text { Endinspiratory pressure } \\
\left(\mathrm{P}_{\mathrm{E}}\right): \leq 30 \mathrm{cmH}_{2} \mathrm{O} \\
\text { Positive endexpiratory } \\
\text { pressure (PEEP) } \geq 5 \mathrm{cmH}_{2} \mathrm{O} \\
\text { Driving pressure }(\triangle \\
\left.\mathrm{P}=\mathrm{P}_{\mathrm{El}} \mathrm{PEEP}\right): \leq 15 \mathrm{cmH}_{2} \mathrm{O}\end{array}$ \\
\hline $\begin{array}{l}\text { Days without organ } \\
\text { dysfunction }\end{array}$ & $\begin{array}{l}\text { Full days without organ } \\
\text { replacement therapy: } \\
\text { Mechanical } \\
\text { ventilation (excluding } \\
\text { atelectasis-prophylaxis). } \\
\text { - Use of vasopressors. } \\
\text { - Renal replacement therapy. }\end{array}$ \\
\hline \multicolumn{2}{|c|}{ Acquired data at hospital discharge } \\
\hline Duration of treatments & $\begin{array}{l}\text { Duration of hospital treatment, } \\
\text { duration of ICU treatment, } \\
\text { duration of hospital treatment } \\
\text { until ARDS diagnosis }\end{array}$ \\
\hline Mechanical ventilation & $\begin{array}{l}\text { Duration of mechanical } \\
\text { ventilation (excluding } \\
\text { atelectasis-prophylaxis) }\end{array}$ \\
\hline Mortality & $\begin{array}{l}\text { In-hospital mortality of ARDS, } \\
\text { ICU mortality of ARDS }\end{array}$ \\
\hline
\end{tabular}

ARDS, acute respiratory distress syndrome; ICU, intensive care unit.

a survey among the app users will be conducted before and after the ASIC app implementation, in order to investigate user acceptance of mobile technical support systems within clinical routine.

\section{Clinical data collection and data protection}

The total data collection started in July 2019 and is scheduled to be completed in December 2021. All data used by the ASIC app or included in the analysis are primarily displayed and stored in the local EHR (tables 1-3). At admission to the ICU, the body height of the patients will be measured using disposable measuring tape in order to determine the predicted body weight for calculating the tidal volume according to ARDS network. ${ }^{13}$ Predicted body weight is computed in men as $50+(0.91 \times$ [height in centimetres -152.4$])$ and in women as $45.5+(0.91 \times[$ height in centimetres - 152.4]). The diagnosis of ARDS is assumed to be made when the international statistical classification of diseases and related health problems (ICD-10) code J80.x is documented, depending on severity of disease. The onset of ARDS in the control phase is defined as the time, when the $\mathrm{p}_{\mathrm{a}} \mathrm{O}_{2} / \mathrm{F}_{\mathrm{i}} \mathrm{O}_{2}$ ratio decreases consistently $\leq 300 \mathrm{~mm} \mathrm{Hg}$, that is, during a period of 2 hours or in two consecutive arterial blood gas analyses, if the time interval between them is longer than 2 hours. During the QIS, the onset of ARDS is assumed, when the physician diagnoses an ARDS using the app. Data are collected from admission to the project until discharge from hospital. Patients who develop ARDS will be assessed for their outcomes when discharged from ICU or 28 days after diagnosis (whatever occurs first) and at hospital discharge depending on the outcome parameter. For a detailed summary, which parameter is collected at which time point, please refer to table 2 .

The data usage takes place within the secure networks of the participating hospitals. When the patient has been discharged, the collected data are transferred to the local Data Integration Centre (DIC), where they are anonymised. The DIC of each location enables medical data sharing across institutional boarders to improve patient care and clinical research. The establishment of these DIC is intended to create a sufficiently large database to allow further analyses. This could help to identify further risk factors with diagnostic or prognostic relevance for ARDS in the future, using, for example, current methods of data science.

Comprehensive validation of data protection issues was carried out by external legal consultants. Furthermore, a data protection concept was developed by external data protection experts for the concrete data protection processes in accordance with the local data protection commissioners (eg, data transfer, anonymisation and data storage).

\section{Proposed sample size}

To check whether the size of the sample we expect to collect in the 12 clusters will suffice to detect a difference in ARDS diagnosis rates with $80 \%$ power, we did a power calculation as proposed by Hussey and Hughes ${ }^{14}$ using the R package swCRTdesign ${ }^{15}$ in $\mathrm{R}$ (V.3.5.1). ${ }^{16}$ This package implements power calculations that take into account the particular characteristics of stepped-wedge cluster-randomised trials such as within-cluster correlations as shown in the article by Hussey and Hughes. ${ }^{14}$

Based on the expected case numbers of 5000 Patients / year, we assumed a mean of 1041 patients per cluster for the study duration of 2.5 years. For the ARDS diagnosis rate in the control phase we used incidences from Brun-Buisson et $a l^{17}$ and Bellani et $a l^{1}$ which suggest a rate of $16.1 \%$ and $23.4 \%$, respectively. Under both of these baseline rates an increase as small as $1 \%$ (eg, from $16.1 \%$ to $17.1 \%$ ) could be detected with at least $80 \%$ power. 


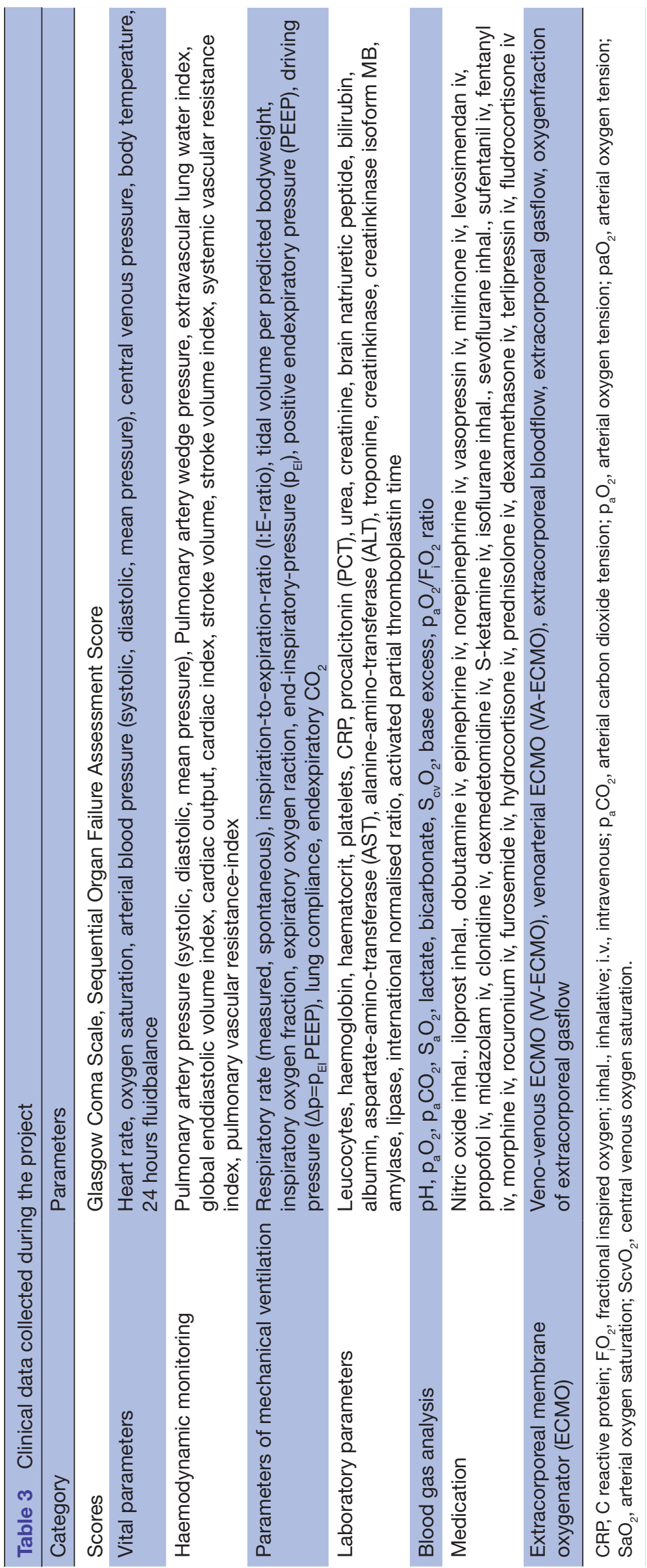




\section{Statistical analysis}

To provide explorative evidence of improvement in healthcare of ARDS patients, differences in primary and secondary KPIs between control phase and QIS will be tested using generalised linear mixed models, where the level of clustering is the 12 clusters. The hypotheses tested for the coprimary KPIs are:

(A) The ARDS diagnosis rate in the QIS phase $\left(p_{\text {OIS }}\right)$ is higher than the rate in the control phase $\left(p_{\text {control }}\right)$ :

$$
H_{0}^{A}: p_{\text {QIS }}=p_{\text {control }} \text { vs. } H_{1}^{A}: p_{\text {QIS }} \neq p_{\text {control }}
$$

(B) The percentage of lung protective ventilation time in the QI phase $\left(p_{\text {OIS }}\right)$ is higher than the percentage in the control phase $\left(p_{\text {control }}\right)$ :

$$
H_{0}^{B}: p_{\text {QIS }}=p_{\text {control }} \text { vs. } H_{1}^{B}: p_{\text {QIS }} \neq p_{\text {control }}
$$

We will conduct two-sided significance tests with a significance level of $5 \%$ and also use point estimates and their $95 \%$ CI to judge the effect. Secondary KPIs will be analysed descriptively and if feasible with exploratory hypothesis tests following the modelling approach of the primary KPIs.

\section{Patient and public involvement}

ASIC is carried out in the routine care of critically ill patients. It fosters the timely diagnose and the adherence to existing guidelines and does not introduce new therapeutic measure. Due to that fact, patients were not included into the planning of the project. During the development of the ASIC app, physicians, who were supposed to use the app, contributed to a user-friendly design of the app. Additionally, surveys among the using physicians will be carried out to evaluate the physician's view onto the app. At last, patient and public involvement will be reached by the SMITH Congresses 2019 and 2022 (https://www.smith.care/) and the activities of the German 'Medical Informatics Initiative' (https://www. medizininformatik-initiative.de/).

\section{Ethics and dissemination}

\section{Ethics review, registration and informed consent}

Ethical approval was obtained from the independent Ethics Commitee (EC) at the RWTH Aachen Faculty of Medicine (local EG reference number: EK 102/19) as well as the respective data commissioner in March 2019. The use case ASIC is registered at the German Clinical Trials Register (DRKS00014330) and will be conducted according to the current version of the Declaration of Helsinki. The collection of routine documentation on which the ASIC app operates does not require an informed consent because the app merely serves as a supplement to the existing EHR, which will remain the main resource in patient data management.

\section{Access to data and dissemination}

The results of the ASIC QIS will be presented at scientific and medical conferences and published in peerreviewed journals. ASIC was created to demonstrate the possibilities offered by advanced digital services and infrastructure in healthcare, and therefore, serves as an exemplary use case with clinical benefit in order to prove the functionality of the DIC infrastructure within the SMITH consortium. One of the main objectives of establishing DIC at the local sites is to facilitate the exchange and use of medical data across the borders of institutions and geographical locations in interoperable data formats for medical research while meeting the data protection and security laws and requirements.

\section{Author affiliations}

${ }^{1}$ Department of Intensive Care Medicine, University Hospital Aachen, Aachen, Germany

${ }^{2}$ SMITH consortium of the German Medical Informatics Initiative, Leipzig, Germany ${ }^{3}$ Juelich Supercomputing Centre, Forschungszentrum Juelich GmbH, Juelich, Germany

${ }^{4}$ Division Information Technology, University Hospital Aachen, Aachen, Germany

${ }^{5}$ Healthcare IT Solutions GmbH, Aachen, Germany

${ }^{6}$ Institute for Computational Biomedicine II, RWTH Aachen University, Aachen,

Germany

${ }^{7}$ Systems Pharmacology \& Medicine, Bayer AG, Leverkusen, Germany

${ }^{8}$ Clinical Pharmacometry, Bayer AG, Leverkusen, Germany

${ }^{9}$ Informatik 11 - Embedded Software, RWTH Aachen University, Aachen, Germany

${ }^{10}$ Department of Anesthesiology and Intensive Care Medicine, Universitätsklinikum Bonn, Bonn, Germany

${ }^{11}$ Staff Unit for Medical and Scientific Technology Development and Coordination, Commercial Directorate, University of Bonn Medical Center, Applied Medical Informatics, Institute for Biometrics, Informatics, and Epidemiology, University Hospital Bonn, Bonn, Germany

${ }^{12}$ Department of Anesthesiology, University Hospital Dusseldorf, Dusseldorf, Germany

${ }^{13}$ IT Department, University Hospital Dusseldorf, Dusseldorf, Germany

${ }^{14}$ Department of Intensive Care Medicine, University Medical Center Hamburg-

Eppendorf, Hamburg, Germany

${ }^{15}$ Research IT, University Medical Center Hamburg-Eppendorf, Hamburg, Germany

${ }^{16}$ IT Department, Data Integration Center, University Hospital Halle, Halle, Germany

${ }^{17}$ Department of Internal Medicine III, Division of Cardiology, Angiology and Intensive Medical Care, University Hospital Halle, Halle, Germany

${ }^{18}$ Department of Anesthesiology and Intensive Care Medicine, Jena University Hospital, Jena, Germany

${ }^{19}$ Institute of Medical Statistics, Computer and Data Sciences, Jena University Hospital, Jena, Germany

${ }^{20}$ IT Department, Data Integration Center, Jena University Hospital, Jena, Germany

${ }^{21}$ Department of Anesthesiology and Intensive Care Medicine, University Hospital Leipzig, Leipzig, Germany

${ }^{22}$ Institute for Medical Informatics, Statistics and Epidemiology, Leipzig University, Leipzig, Germany

${ }^{23}$ Data Integration Center, IT Department, University Hospital Leipzig, Leipzig,

Germany

${ }^{24}$ Department of Anesthesiology and Intensive Care Medicine, Rostock University Medical Center, Rostock, Germany

${ }^{25}$ IT Department, Rostock University Medical Center, Rostock, Germany

Twitter Johannes Bickenbach @bickenbach_j and André Scherag @ScheragAndre Contributors GM and ASchu developed the concept and design of the ASIC use case. OM, SD and JK worked as project managers for the SMITH project and coordinated the use case. SJF, JBK, OM, SD and JB wrote the manuscript. GM, JB, SJF, JBK, CP, SZ, FE, RK, KK, FS, SK, SG, LH, FB, PS, NJ and TS were responsible for the extraction and summary of the guideline recommendations for the ASIC app. VL and NKV developed the technical architecture of the ASIC app and supervised the programming of the ASIC app. SH, IL, SZ, FE, DG, SB, JP, PJ, DT, EW, DA, SM, TW and $P G$ worked on the technical implementation of the DIC at their respective centres and the data extraction for the ASIC app. ASchu, RP, KS, HM, LK, WS, RB, $\mathrm{JL}, \mathrm{MR}, \mathrm{CB}, \mathrm{ASt}$ and $\mathrm{SF}$ worked on the identification of unknown risk factors with diagnostic and prognostic relevance for ARDS. ASche and JP provided feedback regarding the study design and the statistical analysis. GM and VL worked on legal 
issues concerning the implementation of the ASIC app. VL, NV, SH, IL worked on technical issues concerning the implementation of the ASIC app. All authors read and approved the final manuscript.

Funding The SMITH consortium is funded by the German Federal Ministry of Education and Research with the grant code 01ZZ1803A-T. Aachen University Hospital: 01ZZ1803B, Jena University Hospital: 01ZZ1803C, Leipzig University Hospital: 01ZZ1803D, and Halle University Hospital: 01ZZ1803N, Bonn University Hospital: 01ZZ1803Q, Hamburg University Hospital: 01ZZ18030, RWTH Aachen University: 01ZZ1803K, Forschungszentrum Jülich GmbH: 01ZZ1803M, Bayer AG: 01ZZ1803I, University Medical Center Rostock: 01ZZ1803R, Düsseldorf University Hospital: 01ZZ1803T.

Competing interests None declared.

Patient and public involvement Patients and/or the public were involved in the design, or conduct, or reporting, or dissemination plans of this research. Refer to the Methods section for further details.

Patient consent for publication Not required.

Provenance and peer review Not commissioned; externally peer reviewed.

Open access This is an open access article distributed in accordance with the Creative Commons Attribution Non Commercial (CC BY-NC 4.0) license, which permits others to distribute, remix, adapt, build upon this work non-commercially, and license their derivative works on different terms, provided the original work is properly cited, appropriate credit is given, any changes made indicated, and the use is non-commercial. See: http://creativecommons.org/licenses/by-nc/4.0/.

\section{ORCID iDs}

Sebastian Johannes Fritsch http://orcid.org/0000-0002-8350-8584

Julian Benedict Kunze http://orcid.org/0000-0002-7361-1000

Frank Bloos http://orcid.org/0000-0002-0767-7941

André Scherag http://orcid.org/0000-0002-9406-4704

Julia Palm http://orcid.org/0000-0003-1568-5893

Philipp Simon http://orcid.org/0000-0003-2696-3254

\section{REFERENCES}

1 Bellani G, Laffey JG, Pham T, et al. Epidemiology, patterns of care, and mortality for patients with acute respiratory distress syndrome in intensive care units in 50 countries. JAMA 2016;315:788-800.
2 Phua J, Badia JR, Adhikari NKJ, et al. Has mortality from acute respiratory distress syndrome decreased over time?: a systematic review. Am J Respir Crit Care Med 2009;179:220-7.

3 Rubenfeld GD, Caldwell E, Peabody E, et al. Incidence and outcomes of acute lung injury. N Engl J Med 2005;353:1685-93.

4 Adamzik M, Bauer A, Bein T. S3-Leitlinie invasive Beatmung und Einsatz extrakorporaler. Verfahren bei akuter respiratorischer Insuffizienz. AWMF-Leitlinie, 2017. https://www.awmf.org/uploads/ tx szleitlinien/001-021। S3 Invasive Beatmung 2017-12.pdf

5 Amato MBP, Meade MO, Slutsky AS, et al. Driving pressure and survival in the acute respiratory distress syndrome. $N$ Engl $J$ Med 2015;372:747-55.

6 Petrucci N, De Feo C. Lung protective ventilation strategy for the acute respiratory distress syndrome. Cochrane Database Syst Rev 2013:2:CD003844.

7 Herasevich V, Yilmaz M, Khan H, et al. Validation of an electronic surveillance system for acute lung injury. Intensive Care Med 2009;35:1018-23.

8 McKown AC, Brown RM, Ware LB, et al. External validity of electronic sniffers for automated recognition of acute respiratory distress syndrome. J Intensive Care Med 2019;34:946-954.

9 Winter A, Stäubert S, Ammon D, et al. Smart medical information technology for healthcare (Smith). Methods Inf Med 2018;57:e92-105.

10 Semler SC, Wissing F, Heyder R. German medical informatics initiative. Methods Inf Med 2018;57:e50-6.

11 ARDS Definition Task Force, Ranieri VM, Rubenfeld GD, et al. Acute respiratory distress syndrome: the Berlin definition. JAMA 2012;307:2526-33.

12 Hemming K, Haines TP, Chilton PJ, et al. The stepped wedge cluster randomised trial: rationale, design, analysis, and reporting. BMJ 2015;350:h391.

13 Acute Respiratory Distress Syndrome Network, Brower RG, Matthay MA, et al. Ventilation with lower tidal volumes as compared with traditional tidal volumes for acute lung injury and the acute respiratory distress syndrome. N Engl J Med 2000;342:1301-8.

14 Hussey MA, Hughes JP. Design and analysis of stepped wedge cluster randomized trials. Contemp Clin Trials 2007;28:182-91.

15 Hughes J, Hakhu NR. swCRTdesign: stepped wedge cluster randomized trial (SW crt) design. R package version 222018.

$16 \mathrm{R}$ Core Team. R: a language and environment for statistical computing. Austria: R Foundation for Statistical Computing Vienna, 2018.

17 Brun-Buisson C, Minelli C, Bertolini G, et al. Epidemiology and outcome of acute lung injury in European intensive care units. results from the alive study. Intensive Care Med 2004;30:51-61. 